\title{
MicroRNAs as biomarkers of coronavirus disease 2019 (COVID- 19): a scoping review
}

\author{
Marília Berlofa Visacri \\ Department of Pharmacology, School of Medical Sciences, University of Campinas \\ Aline de Souza Nicoletti \\ Department of Pharmacology, School of Medical Sciences, University of Campinas \\ Eder de Carvalho Pincinato \\ Department of Clinical Pathology, School of Medical Sciences, University of Campinas \\ Patricia Moriel ( $\sim$ patricia.moriel@fcf.unicamp.br) \\ Faculty of Pharmaceutical Sciences, University of Campinas
}

\section{Systematic Review}

Keywords: SARS-CoV-2, COVID-19, biomarkers, epigenomics, microRNAs, review

Posted Date: April 30th, 2021

DOl: https://doi.org/10.21203/rs.3.rs-478006/v1

License: (1) (7) This work is licensed under a Creative Commons Attribution 4.0 International License. Read Full License 


\section{Abstract}

Background. Severe acute respiratory syndrome coronavirus 2 (SARS-CoV-2) is a novel coronavirus which was identified as the infectious agent responsible for coronavirus disease 2019 (COVID-19). MicroRNAs (miRNAs) are small non-coding RNAs that can be potential biomarkers of several diseases. The aim of this scoping review was to identify which miRNAs could be biomarkers of COVID19 and their roles.

Methods. A literature search was performed based on PubMed, PubMed Central, BVS/BIREME, Web of Science, Scopus, EBSCOhost, ProQuest, Embase, and Cochrane Library for studies published until January 28th, 2021. Animal and human studies that described miRNAs as biomarkers of SARS-CoV-2 infection/COVID-19 were included. Studies with a purely computational approach were excluded.

Results. A total of 1,797 records were identified, seven of which met the eligibility criteria. Six studies were conducted in humans (samples derived from blood) and one was performed in an animal model (lung tissue). The most important miRNAs identified were miR-195-5p, miR-618, miR-146a-5p, miR-21-5p, miR-15b-5p, miR-142-3p, miR-155, miR-208a, miR-499, miR-103a-2-5p, miR-200c-3p, miR-2115-3p, and members of the let-7 family. Among these miRNAs, miR-146a-5p, miR-21-5p, miR-15b-5p, and members of the let-7 family may be important as they were deregulated in more than one study. Dysregulated miRNAs appear to play key roles in viral replication, proliferation of infected cells, immune response, inflammation, or cardiovascular dysfunction.

Conclusion. MiRNAs may be used as potential diagnostic or severity biomarkers, predictive biomarkers, biomarkers of T-cell immune response, and as therapeutic targets of COVID-19. Further studies are required to investigate and validate the role of miRNAs as biomarkers of COVID-19.

\section{Introduction}

Severe acute respiratory syndrome coronavirus 2 (SARS-CoV-2) is a novel betacoronavirus that was identified as the infectious agent responsible for coronavirus disease 2019 (COVID-19) [1]. After the initial outbreak in Wuhan (China), COVID-19 spread across the world, and was declared a pandemic in March 2020 [2]. At the time of writing of this article (March 2021), more than 100 million cases of COVID-19 had been reported across 223 countries, with 2.7 million deaths [3]. It is worth mentioning that there is no specific treatment available for COVID-19 and that the management of the disease is empirical [4]. To date, only three vaccines have had their emergency use approved by the Food and Drug Administration (FDA), the Pfizer-BioNTech, the Moderna, and the Janssen (Johnson \& Johnson) COVID-19 vaccines [5,6]. However, other vaccines have been approved in other countries.

Real-time reverse transcriptase-polymerase chain reaction (RT-PCR) performed on nasopharyngeal or oropharyngeal swabs is the most widely used diagnostic method for SARS-CoV-2 infection [7]. This technique has been criticized for being relatively invasive and is associated with an increased risk of cross-infection [8]. Serological tests may also be used to diagnose COVID-19. These are based on the detection of SARS-CoV-2 specific antibodies ( $\mathrm{IgM}$ and/or $\lg \mathrm{G}$ ) in blood samples. The detection of $\operatorname{lgM}$ can be interpreted as an indicator of acute infection, whereas the detection of IgG represents previous infection/immunity. However, serological tests have low sensitivity when performed on the first days after the onset of symptoms, have significant rates of false-negative results, and poor validation of results [9]. Chest computed tomography is an alternative test for diagnosing and monitoring COVID-19 [10]. Finally, some inflammatory (procalcitonin, C-reactive protein), hematologic (lymphocyte, thrombocytes), and biochemical (creatine kinase-MB, troponin I, D-dimer, aspartate amino-transferase, alanine amino-transferase, lactate dehydrogenese, gamma-glutamyltransferase) biomarkers have been associated with severe COVID-19 and might help in prognostic risk stratification of patients with COVID-19 [11]. Therefore, identification of effective diagnostic biomarkers and predictors of severity for COVID-19 is becoming increasingly important so that patients can receive an accurate and targeted therapy.

MicroRNAs (miRNAs) are small non-coding ribonucleic acids that are approximately 22 nucleotides long, which enhance messenger RNA (mRNA) degradation and inhibit protein translation [12]. In this way, they play essential regulatory roles in several biological processes and represent potential biomarkers of diseases to be explored [12,13]. Moreover, it is known that virus infection changes host miRNA expression [14] and dysregulated miRNAs have already been studied as biomarkers of several infectious diseases [15]. Thus, miRNAs can also be biomarkers of COVID-19 [16-19]. The aim of this scoping review was to identify which miRNAs could be biomarkers of COVID-19 and their roles. 


\section{Methods}

This review was conducted following the recommendations of the Preferred Reporting Items for Systematic reviews and MetaAnalyses statement for Scoping Reviews (PRISMA-ScR) [20], and the review protocol was registered in the Open Science Framework (https://doi.org/10.17605/OSF.IO/M5VJ6).

2.1. Search strategy. A comprehensive literature search published until January $28^{\text {th }}, 2021$ was performed in the PubMed, PubMed Central, BVS/BIREME, Web of Science, Scopus, EBSCOhost, ProQuest, Embase, and Cochrane Library databases to identify relevant studies. The search strategy included combinations of terms related to COVID-19 and miRNAs. The full strategy search for all databases can be found in the Appendix S1. No language restrictions were applied.

2.2. Study selection. Cell, animal, and human studies that described miRNAs as biomarkers of SARS-CoV-2 infection/COVID-19 were included. Studies with a purely computational approach were excluded. Preprints, books and book chapters, editorials, comments, conference proceedings or abstracts, and literature reviews and guidelines were also excluded. The studies retrieved from the databases were allocated to the Rayyan QCRI program [21] to exclude duplicate files (phase 1), analyze the titles and abstracts of the articles (phase 2), and analyze complete articles whose abstracts were previously selected (phase 3). Two reviewers (MBV and ASN) independently reviewed the titles and abstracts of all studies identified by the searches, and discussed and addressed any discrepancies arising, with a third reviewer (PM). In addition, references cited in all included articles were reviewed to identify any studies that might have been missed.

2.3. Data extraction and analysis. For each included study, information such as author, date of publication or online availability, country, publication type, population, samples, methods used to identify miRNAs, time when miRNAs were analyzed, miRNAs differently expressed in SARS-CoV-2 infected animals/patients with COVID-19, pathophysiological implications of deregulated miRNAs, and the role of miRNAs as biomarkers of SARS-CoV-2 infection/COVID-19 were extracted. Two authors (MBV and ASN) independently completed the data extraction using a preformatted spreadsheet in Microsoft Excel. Disagreements were resolved with a third author (PM). The results of this scoping review are presented as a narrative synthesis. After following the PRISMA-ScR guidelines [20], no quality assessment was performed because scoping reviews aim to identify all the available evidence and highlight their main characteristics, regardless of the quality of such evidence.

\section{Results}

3.1. Search results. The electronic search found 1,797 potentially relevant studies. After removing duplicates and reviewing the titles and abstracts, 29 articles were selected for full-text reading. In addition, no relevant studies were identified by searching the reference lists of the selected studies. After careful full-text reading, only seven studies [22-28] met the inclusion criteria and thus were included in the review. A flowchart of the literature search is shown in Figure 1. The references for the excluded studies, along with the reasons for their exclusion, are available in the Appendix S2.

3.2. Characteristics of the included studies. The characteristics of the seven studies included in this scoping review are summarized in Table 1. All seven studies were published in English, reported between October 2020 and January 2021, and published as research articles [22-28]. Four of them were conducted in China [23-26]. Six studies were conducted in humans [23-28] and one in an animal model [22]. Of the six human studies, five compared patients with COVID-19 with healthy volunteers [23-25,27,28]. Three studies stratified the group of patients with COVID-19 into severity subgroups [24-26]; while one included only patients with mild/moderate disease [23], the other two included only severe/critically ill patients [27,28]. Interestingly, one also compared patients with COVID-19 with patients with influenza-induced acute respiratory distress syndrome (ARDS) [28].

Table 1: Characteristics of the studies included in this scoping review. 


\begin{tabular}{|c|c|c|c|c|}
\hline Author(s) & $\begin{array}{l}\text { Date of } \\
\text { publication } \\
\text { (or online } \\
\text { availability) }\end{array}$ & Country & $\begin{array}{l}\text { Publication } \\
\text { type }\end{array}$ & Population \\
\hline \multicolumn{5}{|l|}{ Animal study } \\
\hline $\begin{array}{l}\text { Kim et al. } \\
{[22]}\end{array}$ & $2020 \mathrm{Nov}$ & Korea & $\begin{array}{l}\text { Research } \\
\text { Article }\end{array}$ & $\begin{array}{l}\text { Hamsters infected by SARS-CoV-2 }(n=5) \text { and uninfected control } \\
\text { hamsters }(n=5) \text {. }\end{array}$ \\
\hline \multicolumn{5}{|c|}{ Human studies } \\
\hline Li et al. [23] & 2020 Oct & China & $\begin{array}{l}\text { Research } \\
\text { Article }\end{array}$ & $\begin{array}{l}\text { Patients with mild or moderate COVID- } 19(n=10 ; \text { gender: } 4 \text { male } / 6 \\
\text { female; mean age: } 44.90 \pm 19.94 \text { years) and healthy volunteers }(n=4 \text {; } \\
\text { gender: } 2 \text { male/ } 2 \text { female; mean age: } 44.75 \pm 11.84 \text { years). }\end{array}$ \\
\hline $\begin{array}{l}\text { Tang et al. } \\
\text { [24] }\end{array}$ & 2020 Oct & China & $\begin{array}{l}\text { Research } \\
\text { Article }\end{array}$ & $\begin{array}{l}\text { Patients with moderate }(n=6 \text {; gender: } 4 \text { male/2 female; range age: } 20- \\
89 \text { years) and severe }(n=6 ; \text { gender: } 5 \text { male/ } 1 \text { female; range age: } 60-89 \\
\text { years) COVID-19, and healthy volunteers ( } n=4 \text {; gender: } 2 \text { male/ } 2 \text { female; } \\
\text { range age: } 50-69 \text { years). }\end{array}$ \\
\hline $\begin{array}{l}\text { Chen et al. } \\
\text { [25] }\end{array}$ & $2020 \mathrm{Dec}$ & China & $\begin{array}{l}\text { Research } \\
\text { Article }\end{array}$ & $\begin{array}{l}\text { Patients with mild (mild or moderate disease }(n=50 \text {; gender: } 28 \\
\text { male/22 female; mean age: } 46.8 \text { years) and severe (severe or critical } \\
\text { disease }(n=16 ; \text { gender: } 12 \text { male/ } 4 \text { female; mean age: } 65.9 \text { years) } \\
\text { COVID-19, and healthy volunteers ( } n=17 \text {; gender: } 9 \text { male/ } 8 \text { female; } \\
\text { mean age: } 32.9 \text { years). }\end{array}$ \\
\hline $\begin{array}{l}\text { Zheng et al. } \\
\text { [26] }\end{array}$ & $2020 \mathrm{Dec}$ & China & $\begin{array}{l}\text { Research } \\
\text { Article }\end{array}$ & $\begin{array}{l}\text { Patients with mild ( } \mathrm{n}=6 \text {; gender: } 4 \text { male } / 2 \text { female; range age: } 3.5-40 \\
\text { years and mean age: } 23.4 \text { years) and moderate }(\mathrm{n}=7 ; \text { gender: } 3 \text { male/ } 4 \\
\text { female; range age: } 32-58 \text { years and mean age: } 49.1 \text { years) and severe }(\mathrm{n} \\
=5 \text {; gender: } 4 \text { male/ } 1 \text { female; range age: } 49-69 \text { years and mean age: } \\
58.0 \text { years) COVID- } 19 .\end{array}$ \\
\hline $\begin{array}{l}\text { Sabbatinelli } \\
\text { et al. [27] }\end{array}$ & $2020 \mathrm{Dec}$ & Italy & $\begin{array}{l}\text { Research } \\
\text { Article }\end{array}$ & $\begin{array}{l}\text { Patients with COVID-19 with multifocal interstitial pneumonia and } \\
\text { requiring oxygen therapy ( } n=29 \text {; gender: } 17 \text { male/ } 12 \text { female; these } \\
\text { patients were divided in two groups for other objective and the mean } \\
\text { age for general group was not shown) and healthy volunteers ( } n=29 \text {; } \\
\text { mean age: } 64.1 \pm 8.6 \text { years). }\end{array}$ \\
\hline $\begin{array}{l}\text { Garg et al. } \\
\text { [28] }\end{array}$ & 2021 Jan & Germany & $\begin{array}{l}\text { Research } \\
\text { Article }\end{array}$ & $\begin{array}{l}\text { Two cohorts: } 1) \text { Discovery cohort: mechanically ventilated COVID- } 19 \\
\text { patients }(n=18 \text {; gender: } 94 \% \text { male/ } 6 \% \text { female; median age: } 59 \text { years }) \\
\text { and healthy volunteers }(n=15 \text {; gender: } 93 \% \text { male/ } 7 \% \text { female; median } \\
\text { age: } 31 \text { years). 2)Validation cohort: mechanically ventilated COVID-19 } \\
\text { patients }(n=20 ; \text { gender: } 70 \% \text { male / } 30 \% \text { female; median age: } 59.5 \\
\text { years), invasively ventilated influenza-induced ARDS patients }(n=13 \text {, } \\
\text { gender: } 85 \% \text { male/ } 15 \% \text { female; median age: } 56 \text { years) and healthy } \\
\text { volunteers ( } n=32 ; \text { gender: } 62.5 \% \text { male/ } 37.5 \% \text { female; median age: } 50 \\
\text { years). }\end{array}$ \\
\hline
\end{tabular}

3.3. MiRNAs as biomarkers of SARS-COV-2 infection/COVID-19. The main results of the included studies involving miRNAs as biomarkers of SARS-CoV-2 infection/COVID-19 are showed in Table 2. In all human studies, analysis was performed to identify miRNAs in samples derived from blood (two used serum [27,28], one used plasma [25], one used red blood cells [24], one used peripheral blood mononuclear cells [26], and one used peripheral blood [23]); the only animal model study used lung tissue [22]. Regarding the methods used to identify miRNAs, four studies used sequencing technology to determine differentially expressed miRNAs [23-26], and three studies quantified miRNAs using PCR $[22,27,28]$. Only five studies reported the time when the miRNAs were analyzed, and no pattern between studies was found [22,23,25-27]; the other two studies did not report this information [24,28].

Many different miRNAs were significantly deregulated in SARS-CoV-2 infection/COVID-19: miR-195-5p, miR-618, miR-146a-5p, miR-215p, miR-15b-5p, miR-142-3p, miR-155, miR-208a, miR-499, miR-103a-2-5p, miR-200c-3p, miR-2115-3p, and members of the let-7 family (let-7a-5p, let-7b-5p, let-7d-5p, and let-7f-5p) [22-28]; however, miR-146a-5p [24,27], miR-21-5p [24,27,28], miR-15b-5p [22,24], and members of the let-7 family $[25,26]$ are highlighted for being deregulated in more than one study. The deregulated miRNAs found appear to play key roles in viral replication, proliferation of infected cells, immune response, inflammation, or cardiovascular dysfunction, contributing to the pathogenesis of COVID-19. Finally, the studies included in this scoping review proposed that 
deregulated microRNAs can be diagnostic [22,23] or severity [24] biomarkers, predictive biomarkers $[25,27,28]$, biomarkers of T-cell immune response [26], and therapeutic targets [23,24] of SARS-CoV-2 infection/COVID-19.

Table 2: MiRNAs as biomarkers in the studies included in this scoping review. 


\begin{tabular}{|c|c|c|c|c|c|c|}
\hline Author(s) & Sample & $\begin{array}{l}\text { Methods } \\
\text { used to } \\
\text { identify } \\
\text { miRNAs }\end{array}$ & $\begin{array}{l}\text { Time when the } \\
\text { miRNAs were } \\
\text { analyzed }\end{array}$ & $\begin{array}{l}\text { Differentially } \\
\text { expressed } \\
\text { miRNAs in } \\
\text { SARS-CoV-2 } \\
\text { infected } \\
\text { animals/patients } \\
\text { with COVID-19 }\end{array}$ & $\begin{array}{l}\text { Pathophysiological } \\
\text { implications of } \\
\text { deregulated miRNAs }\end{array}$ & $\begin{array}{l}\text { Role of miRNAs as } \\
\text { biomarkers of } \\
\text { SARS-CoV-2 } \\
\text { infection/COVID-19 }\end{array}$ \\
\hline \multicolumn{7}{|l|}{$\begin{array}{l}\text { Animal } \\
\text { study }\end{array}$} \\
\hline $\begin{array}{l}\text { Kim et al. } \\
\text { [22] }\end{array}$ & $\begin{array}{l}\text { Lung } \\
\text { tissues }\end{array}$ & qRT-PCR & $\begin{array}{l}4 \text { days post- } \\
\text { infection. }\end{array}$ & $\begin{array}{l}\text { hsa-miR-15b-5p } \\
\text { (downregulated) } \\
\text { hsa-miR-195-5p } \\
\text { (upregulated) } \\
\text { hsa-miR-221-3p } \\
\text { (upregulated) } \\
\text { hsa-miR-140-3p } \\
\text { (downregulated) } \\
\text { hsa-miR-422a } \\
\text { (downregulated) }\end{array}$ & $\begin{array}{l}\text { Downregulation of hsa- } \\
\text { miR-15b-5p may enable } \\
\text { SARS-CoV-2 to escape the } \\
\text { host immune defense by } \\
\text { inhibiting apoptosis and } \\
\text { promote the proliferation } \\
\text { of infected cells. } \\
\text { Upregulation of hsa-miR- } \\
\text { 195-5p promotes } \\
\text { apoptosis by inducing cell } \\
\text { cycle arrest and prevents } \\
\text { excessive proliferation of } \\
\text { the infected cells as the } \\
\text { host immune response. } \\
\text { Upregulation of hsa-miR- } \\
221-3 p \text { can suppress the } \\
\text { innate immune system } \\
\text { and facilitate virus } \\
\text { replication. }\end{array}$ & $\begin{array}{l}\text { hsa-miR-15b-5p } \\
\text { and hsa-miR-195- } \\
5 p \text {, the most } \\
\text { differentially } \\
\text { expressed } \\
\text { compared to other } \\
\text { miRNAs, may } \\
\text { potentially be } \\
\text { diagnostic } \\
\text { biomarkers for } \\
\text { SARS-CoV-2 } \\
\text { infection. }\end{array}$ \\
\hline $\begin{array}{l}\text { Human } \\
\text { studies }\end{array}$ & & & & & & \\
\hline Li et al. [23] & $\begin{array}{l}\text { Peripheral } \\
\text { blood }\end{array}$ & NGS & $\begin{array}{l}\text { A single } \\
\text { sample was } \\
\text { collected for } \\
\text { each patient; } \\
\text { however, this } \\
\text { was done at } \\
\text { different times } \\
\text { within one } \\
\text { week after } \\
\text { diagnosis. }\end{array}$ & $\begin{array}{l}35 \text { miRNAs } \\
\text { (upregulated) } \\
38 \text { miRNAs } \\
\text { (downregulated) } \\
\text { MiRNAs showing } \\
\text { expression fold } \\
\text { changes higher } \\
\text { than 1.3: } \\
\text { miR-16-2-3p } \\
\text { (upregulated, FC } \\
1.56, \text { p < 0.001) } \\
\text { miR-6501-5p } \\
\text { (upregulated, FC } \\
\text { Page 6/16 }\end{array}$ & $\begin{array}{l}\text { Upregulation of miR- } 618 \text { is } \\
\text { related to dysregulation of } \\
\text { immune function. } \\
\text { The article did not explain } \\
\text { the implications of the } \\
\text { other deregulated miRNAs } \\
\text { on SARS-CoV-2 } \\
\text { infection/COVID-19. }\end{array}$ & $\begin{array}{l}\text { miR- } 618 \text { may be a } \\
\text { promising } \\
\text { therapeutic and } \\
\text { diagnostic target to } \\
\text { treat COVID-19 } \\
\text { patients. }\end{array}$ \\
\hline
\end{tabular}


1.74, $p=0.002$ )

miR-618

(upregulated, FC

$1.62, p=0.02$ )

miR-183-5p

(downregulated,

FC 1.30, p <

0.001 )

miR-627-5p

(downregulated,

FC 2.29, p <

0.001)

miR-144-3p

(downregulated,

FC 1.35, $p=$

0.01 )

$\begin{array}{lll}\text { Tang et al. } & \text { Red blood NGS NR } \\ \text { [24] } & \text { cell- } & \\ & \text { depleted } & \\ & \text { whole } & \\ \text { blood } & & \\ & \end{array}$

\section{Severe cases in \\ relation to \\ healthy \\ volunteers (FC $\geq$ 2)}

miR-146a-5p

(downregulated;

$\mathrm{p}<0.001$ )

miR-21-5p

(downregulated:

$\mathrm{p}<0.001$ )

miR-142-3p

(downregulated;

$\mathrm{p}<0.001$ )

miR-3605-3p

(upregulated; $p<$ 0.001)

miR-15b-5p

(upregulated; $p<$ 0.01)

miR-486-5p

(upregulated; $p<$

0.001)

miR-486-3p

(upregulated; $p<$ 0.001)

miR-181a-2-3p

(downregulated;

$\mathrm{p}<0.001$ )

miR-31-5p 3p

(downregulated;

$\mathrm{p}<0.001$ )

miR-99a-5p

(downregulated;

$p<0.001$ )

Moderate cases

in relation to

healthy

volunteers $(F C \geq$ 2)

miR-146a-5p

(downregulated;

$\mathrm{p}<0.001$ )
These miRNAs are

correlated with

inflammation and antiviral

immune responses:

Downregulation of miR-

146a-5p, miR-21-5p, and

miR-142-3p promotes the inflammatory process.

Upregulation of miR-15b$5 \mathrm{p}$ accelerates intracelular viral replication, mediates virus-induced

transcriptome changes,

and intensifies the severity

of COVID-19.

Upregulation of miR-486$5 p$ and miR-486-3p may result in immune response dysregulation.

Downregulation of miR$181 a-2-3 p$ is associated with enhanced TLR4 and CXCL8 expression.

Downregulation of miR$99 a-5 p$ is associated with the expression of the proinflammatory genes IGF1R and MTMR3, inducing weaker antiviral immunity.

The article did not explain the implications of the other deregulated miRNAs on SARS-CoV-2 infection/COVID-19.

Page $7 / 16$ 
miR-21-5p

(downregulated;

$\mathrm{p}<0.001$ )

miR-142-3p

(downregulated;

$\mathrm{p}<0.001$ )

miR-3605-3p

(upregulated; $p<$ 0.05)

Severe cases in relation to

moderate cases

$(\mathrm{FC} \geq 2)$

miR-146a-5p

(downregulated;

$\mathrm{p}=0.049$ )

miR-21-5p

(downregulated;

$p=0.047$ )

miR-142-3p

(downregulated;

$\mathrm{p}<0.05$ )

miR-3605-3p

(upregulated; $p<$ 0.05)

miR-15b-5p

(upregulated; $p$ < 0.05)

miR-486-5p

(upregulated; $p<$ 0.01)

miR-486-3p

(upregulated; $p<$ 0.001 )

miR-181a-2-3p

(downregulated;

$\mathrm{p}<0.001$ )

miR-31-5p 3p

(downregulated;

$\mathrm{p}<0.01$ )

miR-99a-5p

(downregulated;

$\mathrm{p}<0.01$ )

Chen et al. Plasma NGS Sampleswere Among 769

[25]

collected over

exRNAs

a 5-week

period, with 65

compared with

healthy controls,

patients

mild and

severely ill

having more

patients had

significantly

sampling

timepoint.

different

expression

patterns (higher

or lower) in

$39.9 \%$ and $20.5 \%$

exRNAs,

respectively. The

most important

miRNAs were:

Altered expression of let-7

family members, among

exRNAs, revealed the

importance of T-cell

activation and

inflammatory response

suppression.

The article did not explain the implications of the other deregulated miRNAs on SARS-CoV-2

infection/COVID-19.
Let-7 family miRNAs (hsa-let7a-5p, hsa-let-7d$5 p$, and hsa-let-7f$5 p)$ and

hsa-miR-378a-3p, hsa-miR-340-5p hsa-miR-335-3p, and has-miR-98-5p may also be effective predictive biomarkers of clinical outcome at the onset of disease. 


$$
\begin{aligned}
& \text { hsa-let-7a-5p } \\
& \text { hsa-let-7d-5p } \\
& \text { hsa-miR-378a- } \\
& 3 p^{\text {hsa-miR-340- }} \\
& 5 p^{\text {hsa-let-7f-5p }} \\
& \text { hsa-miR-335- } \\
& 3 p^{\text {h }}
\end{aligned}
$$

\begin{tabular}{|c|c|c|c|c|}
\hline \multirow[t]{6}{*}{$\begin{array}{l}\text { Zheng et al. } \\
\text { [26] }\end{array}$} & PBMC & NGS & $\begin{array}{l}\text { At the three } \\
\text { clinical } \\
\text { stages } \\
\text { (treatment, } \\
\text { convalescence, } \\
\text { and } \\
\text { rehabilitation). }\end{array}$ & $\begin{array}{l}\text { In total, } 67 \\
\text { clinical stage- } \\
\text { related } \\
\text { differentially } \\
\text { expressed } \\
\text { miRNAs were } \\
\text { identified. }\end{array}$ \\
\hline & & & & $\begin{array}{l}\text { miRNAs } \\
\text { significantly } \\
\text { deregulated in } \\
\text { the rehabilitation } \\
\text { stage: }\end{array}$ \\
\hline & & & & $\begin{array}{c}\text { let-7b-5p } \\
\text { (downregulated) }\end{array}$ \\
\hline & & & & $\begin{array}{r}\text { miR-103a-2-5p } \\
\text { (downregulated) }\end{array}$ \\
\hline & & & & $\begin{array}{c}\text { miR-200c-3p } \\
\text { (downregulated) }\end{array}$ \\
\hline & & & & $\begin{array}{c}\text { miR-2115-3p } \\
\text { (downregulated) }\end{array}$ \\
\hline
\end{tabular}

Downregulation of let-7b$5 p$ is associated with upregulation of its target gene RASGRPI.

Downregulation of miR$103 a-2-5 p$ is associated with upregulation of its target gene CDK6.

Downregulation of miR$200 c-3 p$ is associated with upregulation of its target gene $Z E B 1$.

\begin{tabular}{|c|c|c|c|}
\hline $\begin{array}{l}\text { Sabbatinelli } \\
\text { et al. [27] }\end{array}$ & Serum & $\begin{array}{l}\text { RT-PCR } \\
\text { and } \\
\text { ddPCR }\end{array}$ & $\begin{array}{l}\text { At baseline } \\
\text { ( 10 days of } \\
\text { onset of } \\
\text { symptoms) }\end{array}$ \\
\hline
\end{tabular}

Downregulation of miR$2115-3 p$ is associated with upregulation of its target gene ATG5.

All these miRNAs regulate $T$ cell differentiation during recovery from COVID-19.

\author{
Patients with \\ COVID-19 \\ showed \\ significantly \\ lower levels of \\ the following \\ miRNAs in \\ relation to \\ healthy \\ volunteers: \\ miR-146a-5p \\ $(\mathrm{MD}=-1.498, \mathrm{p}<$ \\ 0.001) \\ miR-21-5p \\ $(\mathrm{MD}=-0.486, \mathrm{p}$ \\ $=0.025)$ \\ miR-126-3p \\ $(\mathrm{MD}=-0.972, \mathrm{p}$ \\ $<0.001)$ \\ Downregulation of miR- \\ 146a-5p may unleash the \\ release of IL-6. The \\ unbalance of the IL- $6 / \mathrm{miR}$ - \\ $146 a-5 p$ axis could \\ depend, at least in part, \\ from IL-6-stimulating \\ nuclear factors other than \\ NF-KB or synergistically \\ acting with NF-KB, thus \\ dramatically exacerbating \\ IL-6 synthesis without a \\ concomitant induction of \\ miR-146a-5p transcription. \\ Patients with COVID-19 \\ showed increased IL-6 \\ levels and reduced miR- \\ 146a-5p levels compared \\ to healthy subjects, \\ pointing to an imbalance \\ in the IL-6/miR-146a-5p \\ physiological axis in the \\ pathogenesis of SARS- \\ CoV-2 infection.
}

The results showed a robust $\mathrm{T}$-cell immune response, but a weakening innate and humoral immunity during recovery from illness, regardless of the clinical types or disease severity, as

demonstrated by the altered levels of miRNAs let-7b-5p miR-103a-2-5p, miR-200c-3p, and miR-2115-3p involved in $\mathrm{T}$ cell activation and differentiation.
miR-146a-5p, miR21-5p, and miR-126 showed to be biomarkers of a pro-inflammatory state in patients with COVID-19.

Low levels of circulating miR$146 a-5 p$ in patients with COVID-19 may predict poor outcome among those who develop systemic hyperinflammation. 
Downregulation of miR-21-

$5 p$ is associated with

inflammation.

Downregulation of miR-

$126-3 p$ is associated with

inflammation, by

regulating the NF-KB

inhibitor IK-Ba, and

endothelial activation.

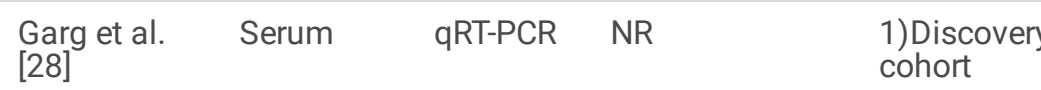

Patients with

COVID-19 in

relation to

healthy

volunteers:

miR-21

(significantly

upregulated)

miR-155

(significantly

upregulated)

miR-208a

(significantly

upregulated)

miR-499

(significantly

upregulated)

miR-126

(significantly

downregulated)

2)Validation

cohort

Patients with

COVID-19 in

relation to

healthy

volunteers:

miR-21

(significantly

upregulated)

miR-155

(significantly

upregulated)

miR-208a

(significantly

upregulated)

miR-499

(significantly

upregulated)
Upregulation of miR-21 is associated with cardiac fibrosis.

Upregulation of miR-155 is associated with inflammation; the markedly elevated levels in COVID-19 might be reflective of endothelialitis.

Upregulation of miR-208a and miR-499 are associated with myocardial/cardiomyocyte damage; higher levels were associated with elevated procalcitonin and lactate.

Downregulation of miR126 is associated with endothelial cell dysfunction.
The upregulation of miR-21, miR-155,

miR-208a, and miR499 in COVID-19 survivors might be predictors of chronic myocardial damage and inflammation.

miRNA profiles were able to differentiate between severely ill patients with COVID-19 and patients with influenza-induced ARDS, indicating a rather specific response and cardiac involvement of COVID-19. 


$$
\begin{aligned}
& \text { Patients with } \\
& \text { COVID-19 in } \\
& \text { relation to } \\
& \text { patients with } \\
& \text { influenza- } \\
& \text { induced ARDS } \\
& \text { patients: } \\
& \text { miR-21 } \\
& \text { (significantly } \\
& \text { upregulated) } \\
& \text { miR-155 } \\
& \text { (significantly } \\
& \text { upregulated) } \\
& \text { miR-499 } \\
& \text { (significantly } \\
& \text { upregulated) }
\end{aligned}
$$

Abbreviations: ARDS, acute respiratory distress syndrome; COVID-19, coronavirus disease 2019; ddPCR, droplet digital polymerase chain reaction; exRNAs, extracellular RNAs; FC, fold change; p, p-value; MD, mean difference; miR, microRNA; miRNAs, microRNAs; NGS, next-generation sequencing; NR, not reported; PBMC, peripheral blood mononuclear cells; qRT-PCR, quantitative real-time polymerase chain reaction; SARS-CoV-2, severe acute respiratory syndrome coronavirus 2 .

\section{Discussion}

Here, we aimed to identify miRNAs as biomarkers of COVID-19 through a literature review. The main findings were as follows: (a) the most important miRNAs, identified as potential candidate biomarkers, were miR-195-5p, miR-618, miR-146a-5p, miR-21-5p, miR-15b5p, miR-142-3p, miR-155, miR-208a, miR-499, miR-103a-2-5p, miR-200c-3p, miR-2115-3p, and members of the let-7 family (let-7a-5p, let-7b-5p, let-7d-5p, and let-7f-5p); (b) miR-146a-5p, miR-21-5p, miR-15b-5p, and members of the let-7 family may play a key role in COVID-19 pathogenesis and severity; (c) the deregulated miRNAs appear to play key roles in viral replication, proliferation of infected cells, immune response, inflammation, or cardiovascular dysfunction; and (d) they may be diagnostic or severity biomarkers, predictive biomarkers, biomarkers of T-cell immune response, and therapeutic targets. To the best of our knowledge, this is the first scoping review regarding miRNAs as biomarkers of COVID-19.

From our perspective, the COVID-19 pandemic changed the profile of published articles; currently, more articles are being published as rapid or short communications with low details. We also noted that many articles only commented on previously published articles, extrapolating the results for SARS-CoV-2 infection, or were about the elucidation of mechanisms, suggesting some important role in SARS-CoV-2 infection. In addition, we found many studies that used only bioinformatics data. Although these characteristics are justified by the urgency demanded by the pandemic and the need for knowledge about this new virus, such articles were excluded from our analysis. Surprisingly, the seven studies included in this scoping review [22-28] were research articles, and six of them were conducted in humans [23-28]; studies on miRNAs as biomarkers have most often been conducted in cells and animal models. Most of the studies were conducted in China [23-26], since this country was the first to be affected by the SARS-CoV-2 [1].

MiRNAs as biomarkers can be detected in several tissues and body fluids, such as blood, urine, saliva, peritoneal fluid, amniotic fluid, bronchial lavage, cerebrospinal fluid, and tears [29]. The studies included in our review used blood and lung tissue samples [22-28]. Though it is important to standardize the time of sample collection for analysis after infection or symptom onset, we observed that there was no standard time for the analysis of miRNAs between studies. Therefore, it was not possible to compare this important parameter. Further research studies with standardized times need to be developed, including more prospective longitudinal studies, to verify how these miRNAs behave over infection time. Moreover, in most human studies [23-26], miRNAs described as potential biomarkers were detected by sequencing, and they need to be validated through RT-PCR in a higher number of patients.

Researchers all over the world have demonstrated that the pathogenesis of severe COVID-19 is associated with hyperinflammation and intensification of the immune effects $[30,31]$. The dysregulated miRNAs highlighted in the included articles are related to viral replication, proliferation of infected cells, immune response, inflammation, or cardiovascular dysfunction [22-28]. All the studies found dysregulated miRNAs probably induced by SARS-CoV-2/COVID-19, indicating that miRNAs are promising to be used as diagnostic or severity biomarkers, predictive biomarkers, biomarkers of T-cell immune response, and therapeutic targets [22-28]. 
Two studies showed miR-146a-5p as a biomarker in COVID-19 [24,27]. This miRNA is important for the activation and function of the immune system [19]. It has been shown that the downregulation of miR-146a-5p promotes the inflammatory process since miR-146a$5 p$ negatively correlates with downstream target mRNA interleukin-1 receptor-associated kinases 1 and 2 (IRAK1 and IRAK2) and tumor necrosis factor receptor-associated factor 6 (TRAF6), which participate in the nuclear factor-kB (NF-kB) proinflammatory pathway [24]. In addition, a decline in miR-146a-5p levels may unleash the release of IL-6 [27]. Therefore, low levels of miR-146a-5p indicate severe COVID-19 and may predict poor outcomes among those who develop systemic hyperinflammation $[24,27]$.

Three studies indicated that miR-21-5p was important for COVID-19 [24,27,28]. Similar to miR-146a-5p, miR-21-5p regulates inflammation and is a marker of the proinflammatory state [27]. In two studies, it was shown that miR-21-5p was downregulated in patients with severe COVID-19 [24,27], whereas it appeared as upregulated in a different study [28]. However, miR-21-5p appeared to be more specific to severe COVID-19 since it was significantly downregulated in patients with severe disease compared to those with moderate disease [24]. Moreover, this miRNA appeared to be more specific of SARS-CoV-2 infection since it was significantly more deregulated in patients with COVID-19 than in patients with influenza-induced ARDS [28]. In a study that evaluated miRNAs as markers of cardiovascular damage in patients with COVID-19, miR-21-5p was associated with cardiac fibrosis and might be a predictor of chronic myocardial damage and inflammation in COVID-19 survivors [28].

Two studies found an association between miR-15b-5p and SARS-CoV-2 infection/COVID-19 [22,24]. Controversially, one study showed that it was downregulated in the lung tissue infected by SARS-CoV-2 [22], whereas others showed that it was upregulated in patients with COVID-19 [24]. A study that used machine learning to predict the likelihood of miRNAs targeting the SARS-CoV-2 genome found a score of 99 in this assessment for miR-15b-5p [32]. Besides directly targeting the viral genome, miR-15b-5p may also regulate the host immune response [33,34]. Thus, miR-15b-5p is associated with viral replication and proliferation of infected cells [22,24], and a decrease in the levels of this miRNA may favor viral replication and host pathogenesis [35]. Kim et al. [22] indicated that this miRNA is a potential diagnostic biomarker for SARS-CoV-2 infection. At the same time, Tang et al. [24] suggested a key role of miR-15b-5p in COVID-19 pathogenesis and patient deterioration, and that it might also be a specific biomarker of severe COVID-19.

Two studies found that members of the let-7 family were deregulated in patients with COVID-19 [25,26]. Both showed the importance of let-7 in T-cell activation $[25,26]$. In fact, let-7 miRNAs play a key role in the activation of the immune system and the inflammation response by targeting IL-6 gene and reducing its expression [19,36]. Downregulation of let-7 family members leads to an intense inflammatory process. Thus, these miRNAs may also be effective predictive biomarkers of clinical outcome [26].

Therefore, miR-146a-5p, miR-21-5p, miR-15b-5p, and members of the let-7 family may serve as important biomarkers of COVID-19. However, more studies including non-COVID-19 patients with pneumonia or ARDS as positive controls for moderate and severe groups as well as asymptomatic COVID-19 patients are required to validate the specificity of these miRNAs as biomarkers [24].

We have included a small number of studies in this scoping review despite the COVID-19 emerging in December 2019 (over a year ago) [1]. In other words, there is a lack of studies evaluating miRNAs as biomarkers of COVID-19. Therefore, we encourage that further primary studies are conducted, mainly including populations from North and South America, where COVID-19 has had a high incidence. This opens a great opportunity to develop new research.

This study has some limitations: some studies may have been missed due to not being indexed in the databases searched. In addition, studies of interest available after the established search period have not been included. Moreover, this review did not analyze the quality of the studies, considering the inherent characteristics of the scoping reviews.

\section{Conclusions}

Overall, there are few studies evaluating miRNAs as biomarkers of SARS-CoV-2 infection/COVID-19. The most important miRNAs identified in the selected articles were miR-195-5p, miR-618, miR-146a-5p, miR-21-5p, miR-15b-5p, miR-142-3p, miR-155, miR-208a, miR-499, miR-103a-2-5p, miR-200c-3p, miR-2115-3p, and members of the let-7 family (let-7a-5p, let-7b-5p, let-7d-5p, and let-7f-5p). Among these miRNAs, miR-146a-5p, miR-21-5p, miR-15b-5p, and members of the let-7 family may play a key role in COVID-19 pathogenesis and severity. Dysregulated miRNAs appear to play key roles in viral replication, proliferation of infected cells, immune response, inflammation control, or cardiovascular dysfunction. These miRNAs may potentially be used as diagnostic or severity biomarkers, predictive biomarkers, biomarkers of T-cell immune response, and therapeutic targets. Further primary studies that demonstrate the role of miRNAs as biomarkers of SARS-CoV-2 infection/COVID-19 are needed.

Page $12 / 16$ 


\section{Declarations}

\section{Conflicts of Interest}

The authors declare that there is no conflict of interest regarding the publication of this paper.

\section{Authors' Contributions}

MBV, ASN, and PM selected the articles and collected data from the studies included. MBV, ASN, and ECP wrote the manuscript. PM revised the manuscript. All authors have read and agreed with the final version of the manuscript.

\section{Funding Statement}

This study was financed in part by the Coordenação de Aperfeiçoamento de Pessoal de Nível Superior - Brasil (CAPES) [Finance Code 001 and 88881.504454/2020-01]. MBV is a recipient of a postdoctoral scholarship from the Coordenação de Aperfeiçoamento de Pessoal de Nível Superior - Brasil (CAPES) [number 88887.504453/2020-00]. ASN is a recipient of a doctoral scholarship from the Coordenação de Aperfeiçoamento de Pessoal de Nível Superior - Brasil (CAPES) [number 88887.511334/2020-00].

\section{Acknowledgments}

We would like to thank the librarian Ana Paula de Morais e Oliveira (School of Medical Sciences of University of Campinas) for all the support offered for conducting this scoping review.

\section{References}

[1] N. Zhu, D. Zhang, W. Wang et al., "A novel coronavirus from patients with pneumonia in China, 2019," The New England journal of medicine, vol. 382, no. 8, pp. 727-733, 2020.

[2] World Health Organization. Coronavirus disease 2019 (COVID-19) situation report -52, https://www.who.int/docs/defaultsource/coronaviruse/situation-reports/20200312-sitrep-52-covid-19.pdf?sfvrsn¹/4e2bfc9c0_4, Accessed 07 Jun 2020.

[3] World Health Organization. Coronavirus disease (COVID-19) outbreak situation, https://www.who.int/emergencies/diseases/novel-coronavirus-2019, Accessed 28 Mar 2021.

[4] M. Phadke and S. Saunik, "COVID-19 treatment by repurposing drugs until the vaccine is in sight," Drug development research, vol. 81 , no. 5 , pp. $541-543,2020$.

[5] S. E. Oliver, J. W. Gargano, M. Marin et al., "The Advisory Committee on Immunization Practices' Interim Recommendation for Use of Pfizer-BioNTech COVID-19 Vaccine - United States, December 2020," MMWR. Morbidity and mortality weekly report, vol. 69, no. 50, pp.1922-1924, 2020.

[6] S. E. Oliver, J. W. Gargano, M. Marin et al., "The Advisory Committee on Immunization Practices' Interim Recommendation for Use of Moderna COVID-19 Vaccine - United States, December 2020," MMWR. Morbidity and mortality weekly report, vol. 69, no. 5152, pp.1653-1656, 2021.

[7] S. Torretta, G. Zuccotti, V. Cristofaro et al., "Diagnosis of SARS-CoV-2 by RT-PCR Using Different Sample Sources: Review of the Literature," Ear, nose, \& throat journal, vol. 100, 2_suppl, pp. 131S-138S, 2021.

[8] J. Adeoye and P. Thomson, "'The Double-Edged Sword' - An hypothesis for Covid-19-induced salivary biomarkers," Medical hypotheses, vol. 143, 110124, 2020.

[9] R. Castro, P. M. Luz, M. D. Wakimoto et al., "COVID-19: a meta-analysis of diagnostic test accuracy of commercial assays registered in Brazil," Brazilian journal of infectious diseases, vol. 24, no. 2, pp.180-187, 2020.

[10] Y. H. Jin, Q. Y. Zhan, Z. Y. Peng ZY et al., "Chemoprophylaxis, diagnosis, treatments, and discharge management of COVID-19: An evidence-based clinical practice guideline (updated version)," Military Medical Research, vol. 7, no. 1, 41, 2020. 
[11] C. Danwang, F. T. Endomba, J. R. Nkeck et al., "A meta-analysis of potential biomarkers associated with severity of coronavirus disease 2019 (COVID-19)," Biomarker research, vol. 8, 37, 2020.

[12] D. P. Bartel, "MicroRNAs: target recognition and regulatory functions," Cell, vol. 136, no. 2, pp. 215-233, 2009.

[13] D. Trzybulska, E. Vergadi, and C. Tsatsanis, "miRNA and Other Non-Coding RNAs as Promising Diagnostic Markers," EJIFCC, vol. 29 , no. 3, pp. 221-226, 2018.

[14] B. R. Cullen, "Five questions about viruses and microRNAs," PLoS pathogens, vol. 6, no. 2, e1000787, 2010.

[15] C. N. Correia, N. C. Nalpas, K. E. McLoughlin et al., "Circulating microRNAs as Potential Biomarkers of Infectious Disease," Frontiers in immunology, vol. 8, 118, 2017.

[16] A. Guterres, C. H. de Azeredo Lima, R. L. Miranda, and M. R. Gadelha, "What is the potential function of microRNAs as biomarkers and therapeutic targets in COVID-19?," Infection, genetics and evolution, vol. 85, 104417, 2020.

[17] R. Mirzaei, F. Mahdavi, F. Badrzadeh et al., "The emerging role of microRNAs in the severe acute respiratory syndrome coronavirus 2 (SARS-CoV-2) infection," International immunopharmacology, vol. 90, 107204, 2021.

[18] F. Abedi, R. Rezaee, A. W. Hayes, S. Nasiripour, and G. Karimi, "MicroRNAs and SARS-CoV-2 life cycle, pathogenesis, and mutations: biomarkers or therapeutic agents?," Cell Cycle, vol. 20, no. 2, pp. 143-153, 2020.

[19] T. Abu-Izneid T, N. AlHajri, A. Mohammed Ibrahim et al., "Micro-RNAs in the regulation of immune response against SARS COV2 and other viral infections," Journal of advanced research, 2020. doi: 10.1016/j.jare.2020.11.013. Epub ahead of print.

[20] A. C. Tricco, E. Lillie, W. Zarin et al., "PRISMA extension for scoping reviews (PRISMA-ScR): checklist and explanation," Annals of internal medicine, vol. 169, no. 7, pp. 467-473, 2018.

[21] M. Ouzzani, H. Hammady, Z. Fedorowicz, and A. Elmagarmid, "Rayyan-a web and mobile app for systematic reviews," Systematic reviews, vol. 5, no. 1, 210, 2016.

[22] W. R. Kim, E. G. Park, K. W. Kang et al., "Expression Analyses of MicroRNAs in Hamster Lung Tissues Infected by SARS-CoV-2," Molecules and cells, vol. 43, no. 11, pp. 953-963, 2020.

[23] C. Li, X. Hu, L. Li, and J. H. Li, "Differential microRNA expression in the peripheral blood from human patients with COVID-19," Journal of clinical laboratory analysis, vol. 34, no. 10, e23590, 2020.

[24] H. Tang, Y. Gao, Z. Li et al., "The noncoding and coding transcriptional landscape of the peripheral immune response in patients with COVID-19”, Clinical and translational medicine, vol. 10, no. 6, e200, 2020.

[25] Y. M. Chen, Y. Zheng, Y. Yu et al., "Blood molecular markers associated with COVID-19 immunopathology and multi-organ damage," The EMBO journal, vol. 34, no. 24, e105896, 2020.

[26] H. Y. Zheng, M. Xu, C. X. Yang et al., "Longitudinal transcriptome analyses show robust T cell immunity during recovery from COVID-19," Signal transduction and targeted therapy, vol. 5, no. 1, 294, 2020.

[27] J. Sabbatinelli, A. Giuliani, G. Matacchione et al., "Decreased serum levels of the inflammaging marker miR-146a are associated with clinical non-response to tocilizumab in COVID-19 patients," Mechanisms of ageing and development, vol. 193, $111413,2021$.

[28] A. Garg, B. Seeliger, A. A. Derda et al., "Circulating cardiovascular microRNAs in critically ill COVID-19 patients," European journal of heart failure, 2021. doi: 10.1002/ejhf.2096. Epub ahead of print.

[29] C. E. Condrat, D. C. Thompson, M. G. Barbu MG et al, "miRNAs as Biomarkers in Disease: Latest Findings Regarding Their Role in Diagnosis and Prognosis," Cells, vol. 9, no. 2, 276, 2020. 
[30] F. Coperchini, L. Chiovato, L. Croce, F. Magri, and M. Rotondi, "The cytokine storm in COVID-19: An overview of the involvement of the chemokine/chemokine-receptor system," Cytokine \& growth factor reviews, vol. 53, pp. 25-32, 2020.

[31] M. Z. Tay, C. M. Poh, L. Rénia, P. A. MacAry, and L. F. P. Ng, "The trinity of COVID-19: immunity, inflammation and intervention," Nature reviews. Immunology, vol. 20, no. 6, pp. 363-374, 2020.

[32] S. Fulzele, B. Sahay, I. Yusufu et al., "COVID-19 virulence in aged patients might be impacted by the host cellular microRNAs abundance/profile," Aging and disease, vol. 11, no. 3, pp. 509-522, 2020.

[33] G. Zhong, X. Cheng, H. Long et al., "Dynamically expressed microRNA-15b modulates the activities of CD8+ T lymphocytes in mice with Lewis lung carcinoma," Journal of translational medicine, vol. 11, 71, 2013.

[34] J. D. Gagnon, R. Kageyama, H. M. Shehata et al., "miR-15/16 Restrain Memory T Cell Differentiation, Cell Cycle, and Survival," Cell reports, vol. 28, no. 8, pp. 2169-2181, 2019.

[35] J. B. De Sanctis, A. García, J. Garmendia et al., "Importance of miRNA in SARS-CoV2 infection," Gaceta médica de Caracas, vol. 128, Supl 1, pp. S1-S6, 2020.

[36] S. Y. Sung, C. H. Liao, H. P. Wu et al., "Loss of let-7 microRNA upregulates IL-6 in bone marrow-derived mesenchymal stem cells triggering a reactive stromal response to prostate cancer", PLoS One, vol. 8, no. 8, e71637, 2013.

\section{Figures}



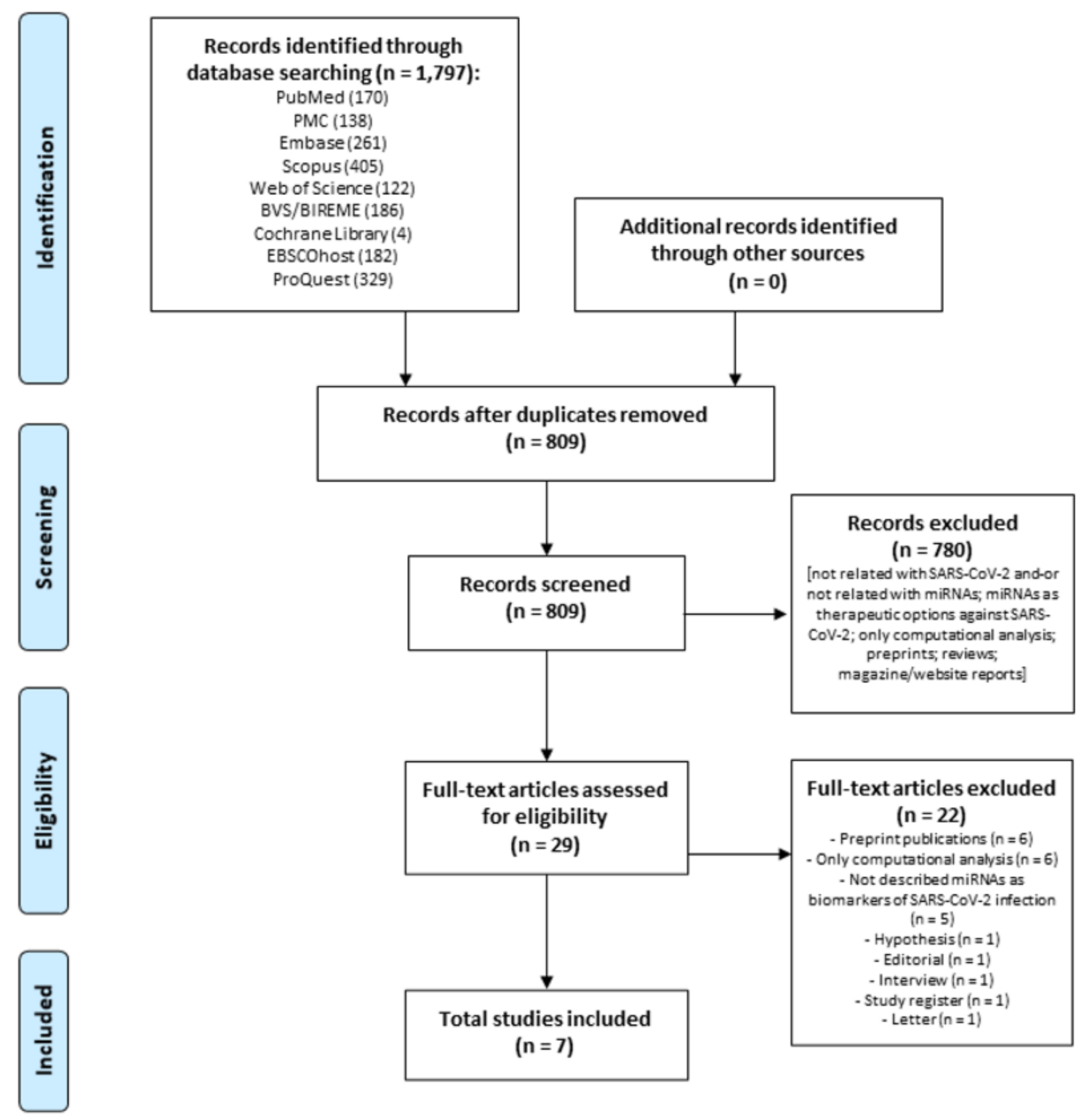

Figure 1

Study selection flowchart through literature search.

\section{Supplementary Files}

This is a list of supplementary files associated with this preprint. Click to download.

- SupplementaryMaterials.docx 